\title{
Mechanisms for stabilisation of baddeleyite in thermally shocked zircon: Evidence from zircon annealing experiments
}

\author{
I. MORALES*, J.F. Molina, P. MONTERO, F. BEA AND
}

A. CAMBESES

Department of Mineralogy and Petrology, University of Granada, Spain (*correspondence: iremoral@ugr.es; jfmolina@ugr.es,pmontero@ugr.es,fbea@ugr.es, acambeses@ugr.es)

Zircon can be subject to thermal shock during the assimilation of crustal rocks by basalts. Although entrapment of zircon grains in mafic phenocrysts can prevent them from dissolving into the basic melt, the thermal shock can trigger zircon breakdown to baddeleyite by reaction with mineral inclusions hosted in the zircon grains, and by recrystallization of metamict zircon. In this work, we simulate these processes using zircon annealing experiments. The results show that the growth of baddeleyite in equilibrium with zircon can take place if there is an efficient mechanism for eliminating the silica excess produced in the zircon-to-baddeleyite reaction. This can be accomplished by silica releasing from the reaction site if zircon grains were permeable enough, and by silica consumption during the generation of zirconbaddeleyite saturated melts via reaction of zircon with its hosted mineral inclusions. A porous medium suitable for silica transport is likely in recrystallized metamict zircon where high porous domains are preserved during the heat treatment, and in zircon with large inheritance where microcracks can propagate by thermo-elastic stress accumulated at the core-rim interface. 